\title{
COMPARATIVE FLEXURAL STRENGTH OF TWO TYPES OF MONOLITHIC ZIRCONIUM OXIDE LONG-SPAN FIXED PARTIAL DENTURES
}

\author{
Mahmoud Abdel Salam Shakal* and Hany Aboulfotouh Abdelmohsen Oraby**
}

\begin{abstract}
Objectives: The purpose of this study was to evaluate the flexural strength of two types of monolithic zirconium oxide long-span fixed partial dentures (FPDs). The monolithic materials used in the study were (InCoris TZI C and Bruxzir shaded 16). Readily prepared ivory teeth were used to simulate a 4-unit FPD with $22 \mathrm{~mm}$ span length. A total number of 40 FPDs 4 units FBDs were distributed into two main groups based on the construction material type, each counting 20 FPDs. Twenty FPDs were fabricated using InCoris TZI C (group 1) and the other twenty FBDs were fabricated using Bruxzir shaded 16 (group 2). FPDs were manufactured according to CAD/CAM technique. All specimens were stored in water for 24 hours and then subjected to 10,000 thermal cycles then mechanically loaded for 10.000 preloading cycles at loads between minimum $10 \mathrm{~N}$ and maximum $89 \mathrm{~N}$ at $1 \mathrm{HZ}$ frequency. and then loaded until failure in a universal testing machine. The 3-point bending test was done to evaluate the flexural strength of the FPDs using Instron testing machine. Results. Bruxzir shaded 16 has recorded the highest mean of values at a level of (928.55 Mpa \pm 66.13 ), while those recorded for InCoris TZI C group of specimens were at the level of (845.21 Mpa \pm 83.54$)$. T-test revealed a highly statistical significant difference between both tested monolithic zirconia materials at the value level of $\mathrm{P}<0.001$.
\end{abstract}

KEY WORDS: Bruxzir shaded 16, InCoris TZI C, flexural strength, long-span FPDs.

\section{INTRODUCTION}

Metal-ceramic restorations technique, has been introduced and widely used in daily practices because of its strength and accuracy of the metal substructure together with the pleasing results because of the ceramic ${ }^{1}$
Despite the attractive advantages provided by the metal ceramic restorations, yet the increasing demand of the public has led to shift researches into all-ceramic restorations in order to cope with the increasing demands for improved esthetics and metal-free dentistry. ${ }^{2}$ The inherent translucency of these materials allows both dentists and technicians to mimic natural teeth. ${ }^{3}$

\footnotetext{
* Assistant professor of Fixed Prosthodontics, Department of Fixed Prosthodontics, Faculty of Dentistry, University of Tanta, Egypt

** Lecturer of Fixed Prosthodontics, Department of Fixed Prosthodontics, Faculty of Dentistry, University of Tanta, Egypt
} 
Zirconium oxide has been used as a core material to provide high strength and porcelain is then fused to the outer surface for improved esthetics. Zirconium oxide proved higher translucency than metal substructures when porcelain is fused to the core substrcture. ${ }^{4}$ The translucency of the veneering porcelain layer allows the color of zirconia core material to show. ${ }^{5}$

However, the increased fracture rate of veneered zirconium oxide compared to metal ceramic restoration as a result of surface grinding, form of loading, inadequate core design and mismatch of the coefficients of thermal expansion. Monolithic zirconia restorations have been introduced into the market to simplify procedures into one step and reduce the risk possibility of veneering fracture. ${ }^{6}$ Monolithic form of Zirconia restorations is indicated particularly for posterior zone. The zirconia cubic phase incorporation offers a promising avenue to increase the material's translucency. However, this cubic zirconia does have $20 \%$ lower flexural strength than traditional yttria- or ceria-stabilized zirconia formulations. ${ }^{7}$

Monolithic zirconia offers a great advantage with certain conditions such as history of restoration fracture, compromised occlusal schemes and parafunctional habits. The overall esthetics of zirconia restoration has been improved over the last few years, as a result of decreasing the degree of their opacity that in turn has improved the ability of monolithic zirconia restoration to mimic natural teeth appearance of the posterior restorations. ${ }^{8}$

Regardless the relatively opaque monolithic zirconium oxide crowns, they offer more advantages over metal-ceramic, such as conservation of the natural tooth structure and compared to glass-based all-ceramic crowns as a result of the improved mechanical properties of the monolithic material such as flexural strength and fracture toughness reducing fracture and chipping potential associated with the use of veneering porcelain. ${ }^{9}$ Moreover the restoration can be shaded after milling before sintering making their manufacturing process more simplified and faster.

The opacity degree of the yttria stabilized tetragonal zirconia polycrystalline (Y-TZP) ceramics and the degree of its translucency without compromising their strength properties can be varied depending on sintering conditions as reported by Kim et $\mathrm{al}^{3}$.

Shifting from restricting the BruxZir restorations material from being a posterior solution to being an anterior option as well, because of its high strength and fit together with the substantially improvement. ${ }^{10}$ The BruxZir Shaded 16 zirconia manufacturer claims that the unique colloidal and pressed processing techniques that differ from other processing methods results in an improved optical property. BruxZir Shaded 16 requires no color dipping or staining as they are provided in series of 16 pre-shaded pressed zirconia blanks that match all of the VITA Classical shades that ensures complete and consistent shade penetration (VITA North America).$^{10}$

In-Coris TZI C ceramic (Dentsply Sirona) is presented as per-shaded zirconia blocks that do not require other steps for shading after milling, accelerating the production of fully anatomical esthetically pleasing restorations, while maintaining high strength, biological compatibility, resistance to corrosion as claimed by the manufacurer. ${ }^{11}$

Restorative material strength is a critical mechanical property specially with long-span restorations, whereas fracture of the restoration is more likely with long span than with short ones. ${ }^{12}$, The biomechanical bending of the restoration under masticatory function varies with the cube of the length, where replacing two teeth might be susceptible to fracture eight times as much as a single tooth replacement and replacing three teeth might cause the fixed restoration to bend twentyseven times as much as a single tooth replacement. 
leading to the conclusion increasing the span of a fixed restoration, might results in inevitable cracks induction and propagation or even fracture of ceramic restoration and disappointing results. ${ }^{1 .}$

Therefore, this study was directed to compare and evaluate the flexure strength of two types of monolithic zirconium oxide long-span fixed partial dentures.

\section{Aim of the study}

The aim of this study was to compare and evaluate the flexural strength of two types of monolithic zirconium oxide long-span fixed partial dentures.

\section{MATERIAL AND METHODS}

TABLE (1): Materials used in the study

\begin{tabular}{|c|c|c|}
\hline Materials & Composition & Manufacture \\
\hline $\begin{array}{l}\text { Readymade } \\
\text { prepared } \\
\text { ivory teeth }\end{array}$ & $\begin{array}{l}\text { inorganic formula } \\
\mathrm{Ca}_{10}\left(\mathrm{PO}_{4}\right)_{6}\left(\mathrm{CO}_{3}\right) \cdot \mathrm{H}_{2} \mathrm{O} \\
\text { (collagen matrix ,mineral } \\
\text { component) }\end{array}$ & $\begin{array}{l}\text { Nissin Dental } \\
\text { Products INC, } \\
\text { Kyoto, Japan. }\end{array}$ \\
\hline $\begin{array}{l}\text { Bruxzir } \\
\text { shaded } 16 \\
\text { blanks }\end{array}$ & $\begin{array}{l}\text { High translucent zirconia } \\
\text { Y-TZP altered grain size } \\
\text { and/or added other dopants, } \\
\text { e.g. alumina. }\end{array}$ & $\begin{array}{l}\text { Glidewell } \\
\text { Laboratories; } \\
\text { Newport Beach, } \\
\text { Calif.. USA } \\
\end{array}$ \\
\hline $\begin{array}{l}\text { InCoris } \\
\text { TZI C } \\
\text { blocks }\end{array}$ & $\begin{array}{l}\text { Translucent pre-dyed } \\
\text { zirconia ceramic blocks } \\
\mathrm{ZrO} 2+\mathrm{HfO} 2+\mathrm{Y} 2 \mathrm{O} 3 \geq 99.0 \% \\
\mathrm{Y} 2 \mathrm{O} 3>4.5-\leq 6.0 \% \\
\mathrm{HfO} 2 \leq 5 \% \\
\mathrm{~A} 12 \mathrm{O} 3 \leq 0.04 \% \\
\text { Other oxides } \leq 1.1 \%\end{array}$ & $\begin{array}{l}\text { Sirona Dental } \\
\text { Systems } \\
\text { GmbH, } \\
\text { Bensheim, } \\
\text { Germany }\end{array}$ \\
\hline $\begin{array}{l}\text { Adhesive } \\
\text { luting resin } \\
\text { cement }\end{array}$ & $\begin{array}{l}\text { Methacrylate monomers } \\
\text { self-adhesive (RelyX } \\
\text { Unicem) }\end{array}$ & $\begin{array}{l}\text { 3M ESPE, St. } \\
\text { Paul, MN, USA }\end{array}$ \\
\hline
\end{tabular}

\section{Sample preparation}

Readily prepared lower first premolar and second molar ivory teeth (Nissin Dental Products INC, Kyoto, Japan) with standardized preparation (1.5 $\mathrm{mm}$ occlusal reduction, 6-degree total convergence and shoulder finish line with 1-mm width.) were mounted vertically with their long axis at $2 \mathrm{~mm}$ below cemento-enamel junction (CEJ) in an acrylic block at a distance of $22 \mathrm{~mm}$ representing the length of span for a missing lower second premolar and lower first molar (Fig. 1).

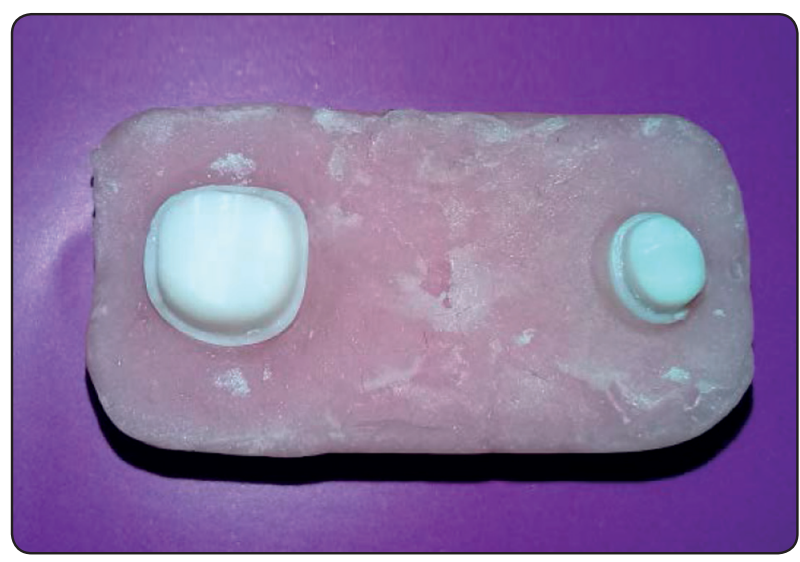

Fig. (1) Mounted abutments set up

The mounted teeth with the acrylic blocks complex of specimens were used to construct a 4-unit FPD with the two-different group of zircon materials tested in the study.

The 4 units span FPDs were distributed into two main groups based on the material of construction each counting twenty FPDs. Twenty FPDs were fabricated using (InCoris TZI C) (Group. 1) and the other twenty FBDs (Group. 2) were fabricated using (Bruxzir shaded 16). FPDs were manufactured according to $\mathrm{CAD} / \mathrm{CAM}$ technique. Specimens grouping and subgroupings are shown in table (2).

TABLE (2) Specimens grouping and distribution in the study

\begin{tabular}{|c|c|}
\hline $\begin{array}{c}\text { Group (1) } \\
\text { 4 Units FPD (N=20) }\end{array}$ & $\begin{array}{c}\text { Group (2) } \\
\text { 4 Units FPD (N=20) }\end{array}$ \\
\hline InCoris TZI C & Bruxzir shaded 16 \\
\hline
\end{tabular}




\section{Construction of the fixed partial dentures}

The mounted readily prepared teeth with the acrylic blocks were scanned in (Q700 Scanners, 3Shape, Copenhagen, Denmark) for CAD/CAM processing (Fig.2)

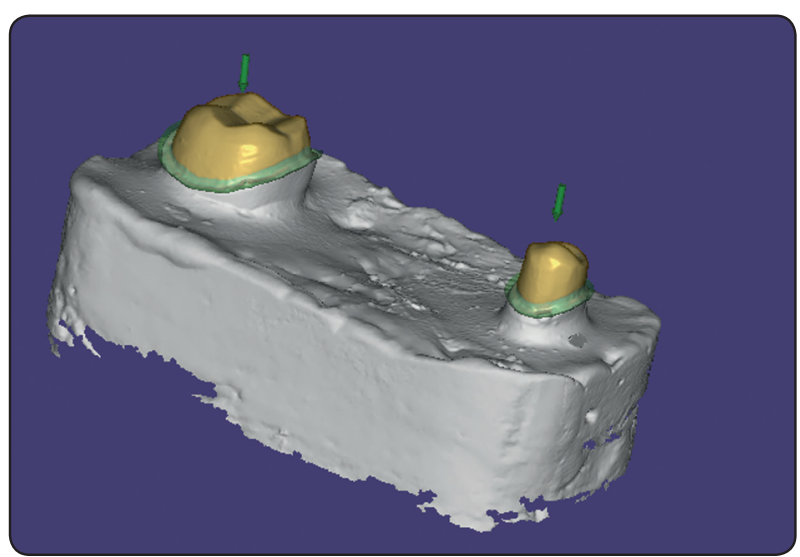

Fig. (2) Scanned abutments

A fully contoured 4 units FPDs with standardized design were done using CAD software (Dental System, 3Shape, Copenhagen, Denmark) for both material types as follow, sanitary pontics were designed with $3.5 \mathrm{~mm}$ connector width in both mesiodistal and buccolingual directions, while the occluso-cervical dimension of the connector was kept at $2.5 \mathrm{~mm}$ (Fig.3).

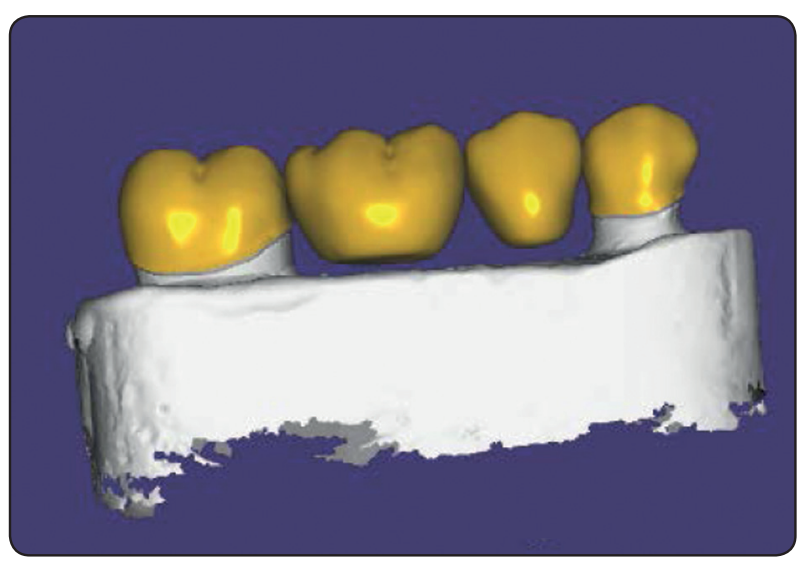

Fig. (3) Four units FPD Design
The 4 units FPDs were milled out of InCoris TZI C blanks for (Group1) specimens or Bruxzir shaded 16 for Group 2 specimens Cerec CAD/CAM milling process. All 40 FPDs of both groups were sintered at $1530^{\circ} \mathrm{C}$ in a high-temperature furnace (ZYRCOMAT 600 MS, VITA Zahnfabrik, Bad Säckingen, Germany) for 2 hours. Following the manufacturer's instructions.

\section{Specimens cementation}

All FPDs retainers were cemented using selfadhesive luting cement (RelyX ${ }^{\mathrm{TM}}$ Ultimate, 3M ESPE, St Paul, MN, USA) with the application of seating forces of $30 \mathrm{~N}$ to their corresponding ivory abutment teeth. All cemented FPDs were stored in distilled water at room temperature for $24 \mathrm{~h}$ before samples stressing in chewing simulator.

\section{Specimens aging:}

All FPDs specimens of both materials groups (G1 and G2) were then subjected to 10,000 thermal cycles with temperature range of $\left(5-55^{\circ} \mathrm{C}\right)$ with a 30-s dwell time, 20 seconds transfer time, that corresponds to one year of clinical service. The thermocycled FPDs of both groups were subjected to 10.000 preloading cycles at loads between minimum $10 \mathrm{~N}$ and maximum $89 \mathrm{~N}$ at $1 \mathrm{HZ}$ frequency. The rate used was equivalent to the average masticatory cycle ( 0.8 to 1.0 cycle/sec..$^{13}$

\section{Flexural strength test}

FPDs of both groups were mounted and jigged to a universal testing machine (Instron 3365, High Wycombe, UK). Flexure strength of the FPDs were evaluated by three points bending by applying a vertical load through a $4.2 \mathrm{~mm}$ diameter steel bar at a crosshead speed of $1 \mathrm{~mm} / \mathrm{min}$ occlusally on the mid-way pontic area. Load continued until specimen's fracture occurs. (Figure. 4). The maximum load causing bridge failure was recorded in $\mathrm{MPa}$ 


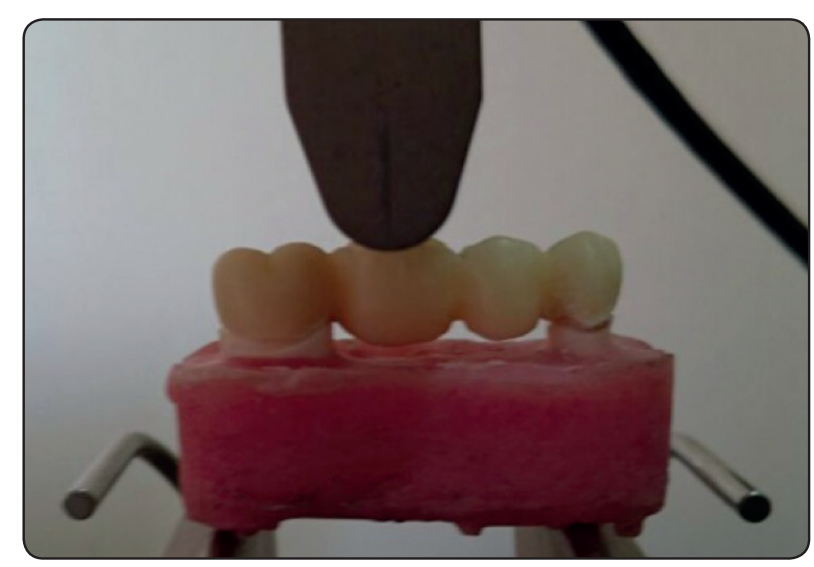

Fig. (4) FPD flexure testing

Flexural strength values were calculated from the following formula:

$$
\begin{aligned}
\text { Flexural strength } & =\frac{3 \times \text { Load } \times \text { Length }}{2 \times \text { Width } \times \text { Thickness }^{2}} \\
\sigma & =\frac{3 P L}{2 b d^{2}}
\end{aligned}
$$

Where:

$\mathrm{F}=$ Loading force at fracture point

$\mathrm{L}=$ Length of supporting span " $22 \mathrm{~mm}$ "

$$
\mathrm{b}=\text { Width "4 mm" }
$$

$\mathrm{d}=$ depth of FPD specimen " $1.3 \mathrm{~mm}$ "

The recorded values of flexure strength for both groups were collected and analyzed using Statistical Package for Social Sciences (SPSS version 21). One-way analysis of variance (ANOVA) test was used. Mean \pm standard deviations (SD) of flexure strength values (MPa)) were calculated and analyzed statistically with descriptive statistics. Independent student $\mathrm{T}$ significance test was conducted where $\mathrm{P}<0.001^{* *}$ mean significance.

\section{RESULTS}

The flexural strength means values, \pm standard deviations for both tested materials of the monolithic zirconia long-span FPDs are presented in table (3), and represented graphically in box blots figure (5). Bruxzir shaded 16 (928.55 Mpa \pm 66.13) recorded higher flexural strength mean value than InCoris TZI C (845.21 Mpa \pm 83.54$)$. T-test revealed a highly statistical significant difference between both tested monolithic zirconia materials at the value level of $\mathrm{P}<0.001$.

TABLE (3): T-test of the flexural strength means

\begin{tabular}{|c|c|c|c|c|}
\hline & $\begin{array}{c}\text { Group 1 } \\
\text { (InCoris } \\
\text { TZI C) }\end{array}$ & $\begin{array}{c}\text { Group 2 } \\
\text { (Bruxzir } \\
\text { shadad 16) }\end{array}$ & $\mathrm{t}$ & Sig. \\
\hline $\begin{array}{c}\text { Flexural } \\
\text { strength } \\
\text { (Mpa) }\end{array}$ & $\begin{array}{c}845.21 \pm \\
83.54\end{array}$ & $\begin{array}{c}928.55 \pm \\
66.13\end{array}$ & -3.498 & $0.001 * *$ \\
\hline
\end{tabular}

**; High Statistical Significant difference

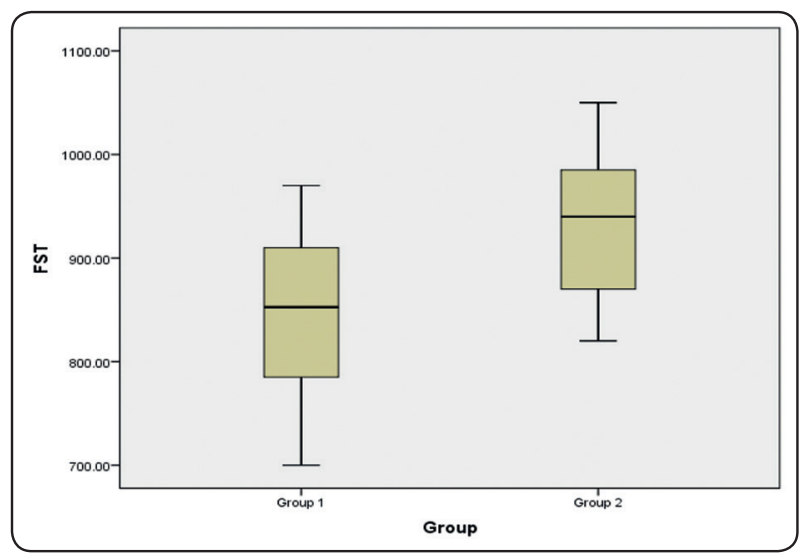

Fig. (5): Box plots of flexural strength mean values of the FPDs.

\section{DISCUSSION}

The superior strength properties of zirconia materials compared to all ceramic restorations has made them of a prime choice as a material for fixed prosthetic restoration recently. However, veneering the outer surface of the zirconia substructure with porcelain to maximize the esthetic outcome has encountered problem involves chipping and fracture of the porcelain from the underlying zirconia material. The increased fracture incidence rate of the bilayered restoration and the introduction of a more translucent zirconia without compromising its mechanical properties is one of the main reasons that monolithic zirconia restorations have become popular. ${ }^{6}$ 
Although thermal and mechanical cycling combined are unusual on zirconia studies Samples design and dimensions of both groups in the present study, were identical, therefore both groups are comparable. ${ }^{14}$

A physiologic range of occlusal forces load was applied on the tested samples based on range and limits reported in previous studies. ${ }^{13}$ Subjecting the samples to thermal and mechanical loading to mimic active oral environmental condition as part of the present study design, representing the expected clinical in vivo changes, which might result in the undesired phenomenon of low temperature degradation (LTD).$^{15}$

Survival of all FPDs samples of both groups after artificial aging in the chewing simulator, indicates the stable performance of the zirconia ceramics under mechanical and thermal stress like in the oral environment, as previously reported. ${ }^{15,16}$

3-point flexure test until fracture estimates the material's resistance under bending, which is a common form of stress in Prosthetic Dentistry was used in the current study as previously reported..$^{17,18,19}$. Both types of tested monolithic zirconia recoded high flexural strength mean values, whereas, Bruxzir shaded 16 recorded a higher flexural strength mean value $(928.55 \pm 66.13)$ than InCoris TZI C (845.21 \pm 83.54$)$ with significance $(\mathrm{P}<0.001)$. These results coincide with the outcome of the comparative study conducted by Church TD et al., 2017 comparing the flexural strength modulus and translucency of 6 ceramic materials and stated that Bruxzir shaded 16 zirconia had a better combination of flexural strength modulus and translucency ${ }^{20}$.

\section{CONCLUSIONS}

Within the limitations of this in-vitro study, clinically acceptable flexural strength mean values were demonstrated with the tested monolithic zirconia restorations. Bruxzir shaded 16 shows higher flexural strength mean value than InCoris
TZI C when used to fabricate long-span FPDs. Artificially aging the long span FPDs with both types of the tested materials had a minimal effect on the flexural strength value reflecting, the durability of this type of restorations intraorally.

\section{REFERENCES}

1- Shillingburg HT Jr, Sather A, Wilson EL, et al. Fundamentals of Fixed Prosthodontics. 4th ed. Hanover Park, IL: Quintessence; 2012:433-455.

2- Heffernan MJ, Aquilino SA, Diaz-Arnold AM, Haselton DR, Stanford CM, Vargas MA. Relative translucency of six all-ceramic systems, I: core materials. J Prosthet Dent. 2002;88(1):4-9.

3- Kim MJ, Ahn JS, Kim JH, Kim HY, Kim WC. Effects of the sintering conditions of dental zirconia ceramics on the grain size and translucency. J Adv Prosthodont. 2013;5(2):161-166.

4- Spyropoulou PE, Giroux EC, Razzoog ME, Duff RE. Translucency of shaded zirconia core material. J Prosthet Dent. 2011;105(5):304-307.

5- Al-Amleh B, Lyons K, Swain M. Clinical trials in zirconia: a systematic review. J Oral Rehabil.2010;37(8):641-652.

6- Lawson NC, Burgess JO. Dental ceramics: a current review. Compend Contin Educ Dent. 2014;35(3):161-166.

7- Gionea A, Andronescu E, Voicu G, Bleotu C, Surdu VA. Influence of hot isostatic pressing on $\mathrm{ZrO}(2)-\mathrm{CaO}$ dental ceramics properties. Int J Pharm. 2015 Oct 23.

8- Wall JG, Cipra DL. Alternative crown systems. Is the metal-ceramic crown always the restoration of choice? Dent Clin North Am. 1992 Jul; 36(3):765-82.

9- Ilie N, Stawarczyk B. Quantification of the amount of light passing through zirconia: the effect of material shade, thickness, and curing conditions. J Dent. 2014; 42(6):684-690.

10- Glidewell Laboratories. BruxZir [product information]. 2016. http://glidewelldental.com/services/bruxzir-solidzirconia/bruxzir-milling-blanks. Accessed November 17, 2016.

11- Dentsply Sirona. CAD/CAM Materials for Dental Practices [product information]. http://www. sironausa. com/us/products/digital-dentistry/cad-cam-materialspractice $/$ ?tab=4312. Accessed November 17, 2016 . 
12- Spear F. An interdisciplinary approach to the use of longterm temporary restorations. J Am Dent Assoc 2009; 140:1418-1424.

13- Hamza TA, Sherif RM. Fracture resistance of monolithic glass- ceramics versus bilayered zirconia- based restorations. J of prosthodont 2017; 19: 1-6.

14- Vidotti HA, Pereira JR, Insaurralde E, de Almeida AL, doValle AL. Thermo and mechanical cycling and veneering method do not influence Y-TZP core/veneer interface bond strength. J Dent 2013; 41: 307-312.

15- Lameira DP, Buarque e Silva WA, Andrade e Silva F, De Souza GM. Fracture strength of aged monolithic and bilayer zirconia-based crowns. Biomed Res Int 2015; 2015: 418641.

16- Guess PC, Schultheis S, Wolkewitz M, Zhang Y, Strub JR.Influence of preparation design and ceramic thicknesses on fracture resistance and failure modes of premolar partial coverage restorations. J Prosthet Dent 2013; 110: 264-273.

17- Sundh A, Molin M, Sjogren G. Fracture resistance of yttrium oxide partially-stabilized zirconia all-ceramic bridges after veneering and mechanical fatigue testing. Dent Mater 2005; 21: 476-482.

18- Guazzato M, Proos K, Sara G, Swain MV. Strength, reliability,and mode of fracture of bilayered porcelain/core ceramics. Int J Prosthodont 2004; 17: 142-149..

19- Homaei E, Farhangdoost K, Tsoi JK, Matinlinna JP, Pow EH. Static and fatigue mechanical behavior of three dental CAD/CAM ceramics. J Mech Behav Biomed Mater. 2016;59:304-313.

20- Church TD, Jessup JP, Guillory VL and Vandewalle KS. Translucency and strength of high translucency monolithic zirconium oxide materials. J Gene Dent. 2017:48-52. 